بناء أنموذج رياضي لمشكلتش النقل في ظل قيود ديناميكيت الطلب مع تطبيق عملي لئي

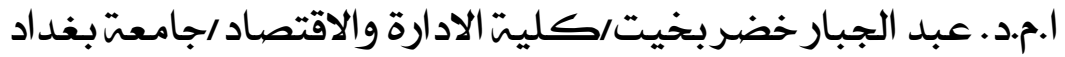

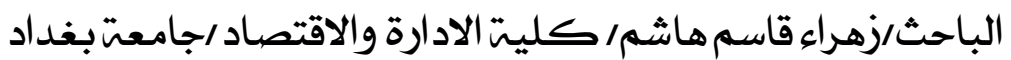

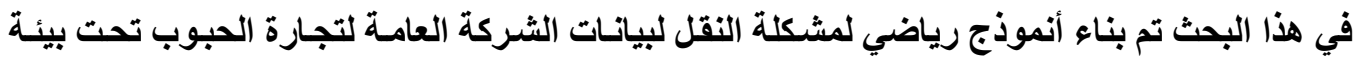

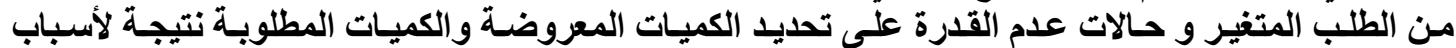

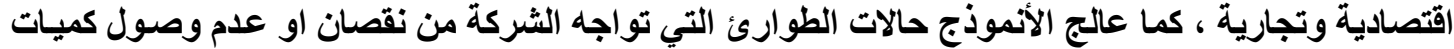

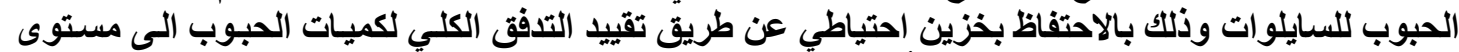

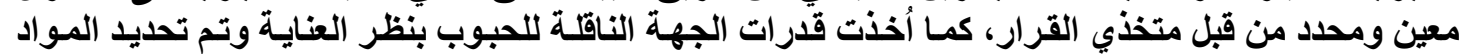

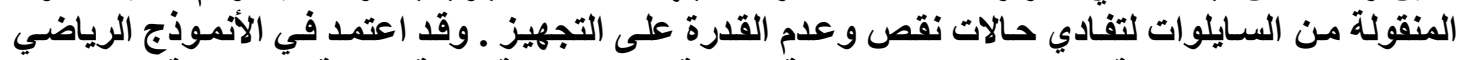

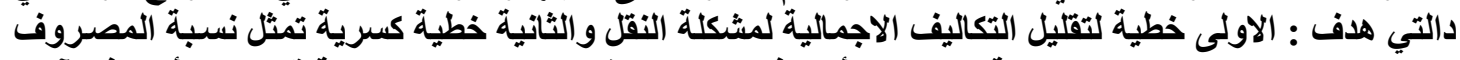

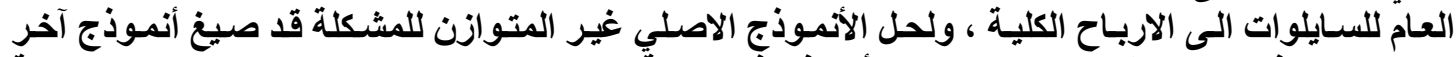

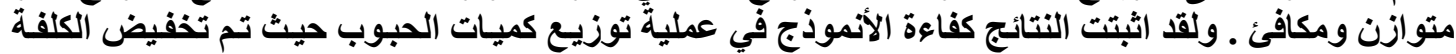

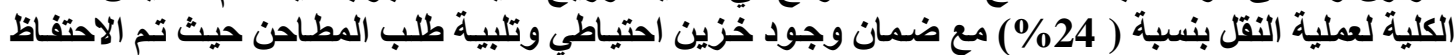

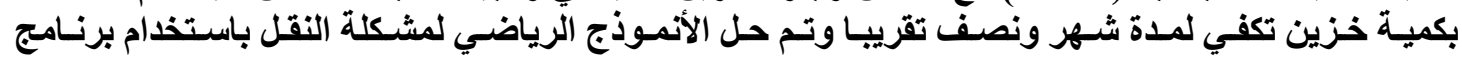
. ( LINGO14.0)

الاصطالمات الرئيسية لابحث / مشكلة النقل المقيدة ، خطية زائدا خطية كسرية ،تدفق مقيد

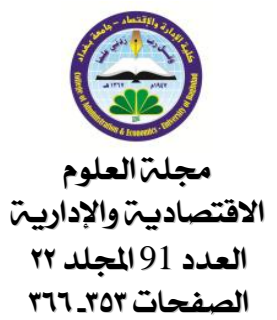


بناء أنموزح رياضي لمشكلة النقلا فحي ظلا قيود ريناميكية الطلب مع تطبيقا عمليي

(1) (1) (المدهمة

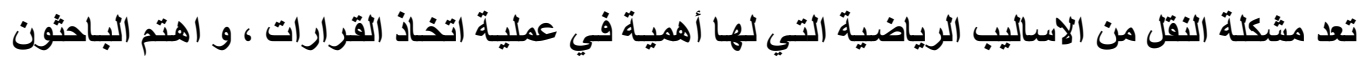

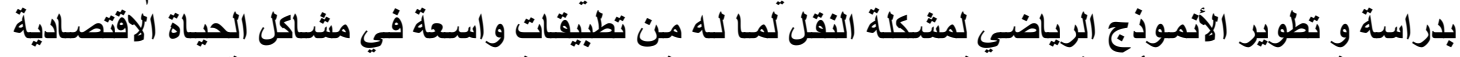

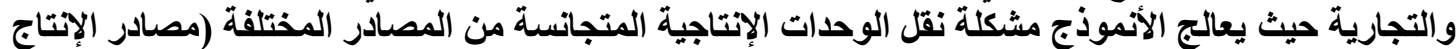

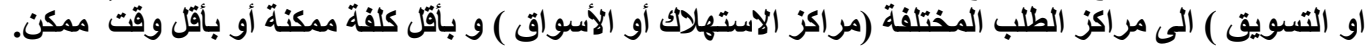

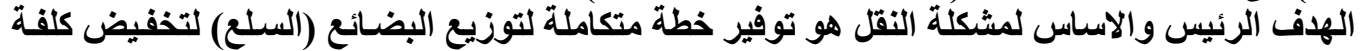
النقل الى اقل ما يمكن وتحقيق الطلب.

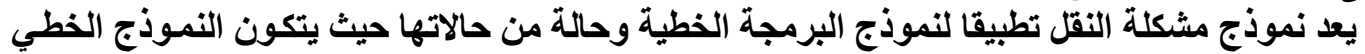

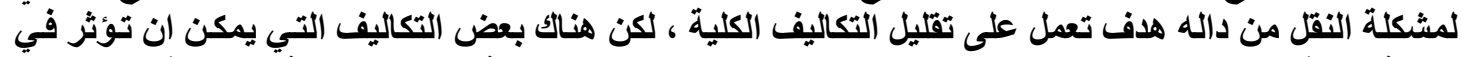

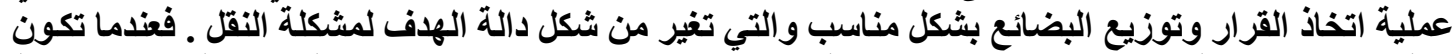

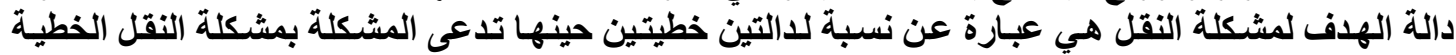

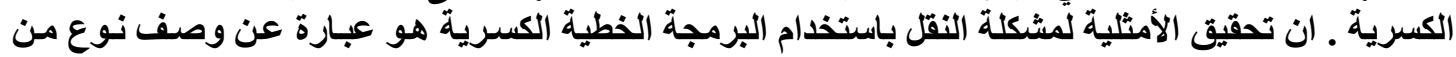

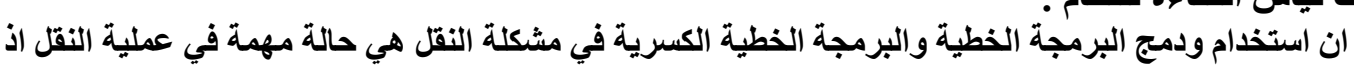

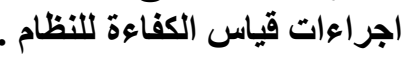

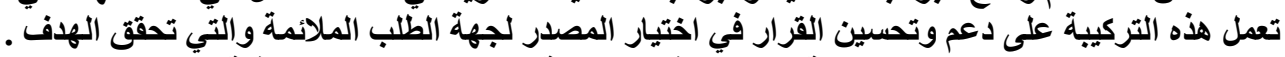

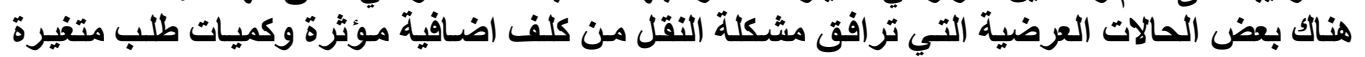

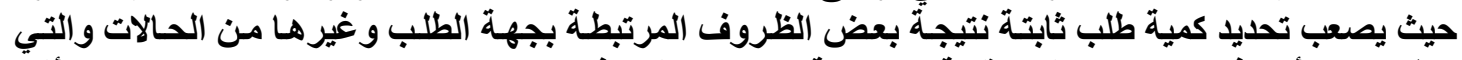

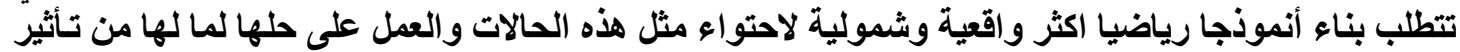

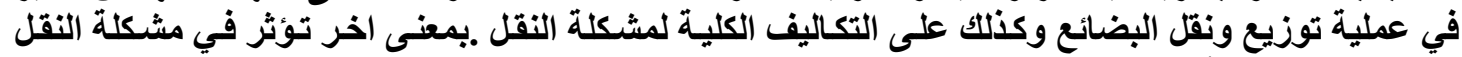

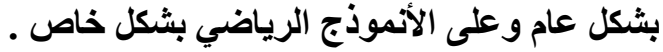

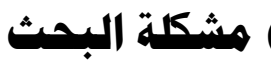

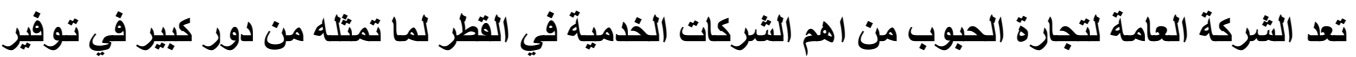

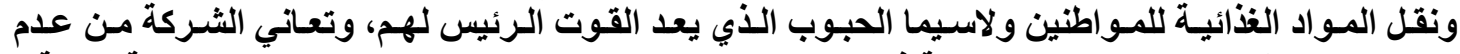

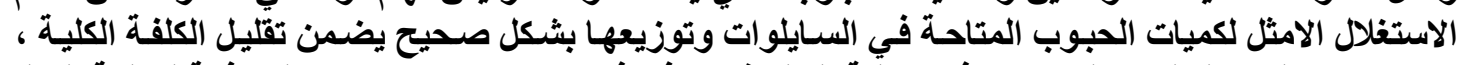

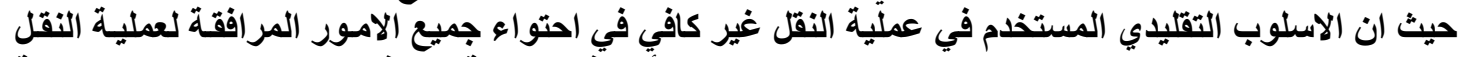

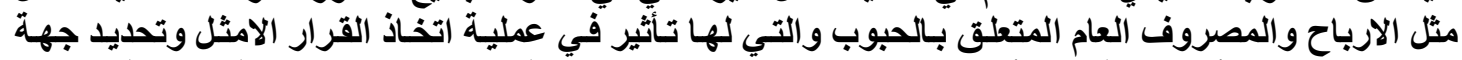

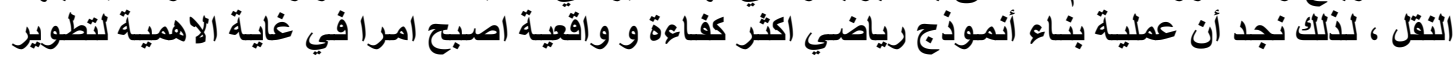
عملية النقل في الثركة.

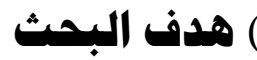
(3)

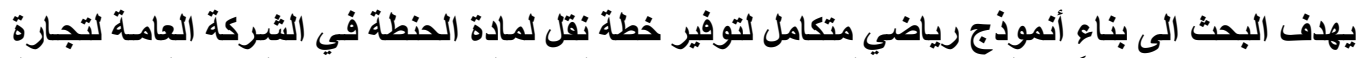

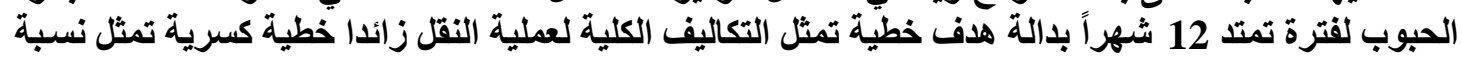

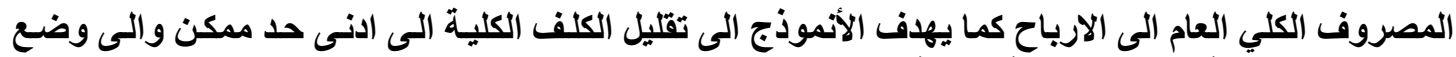

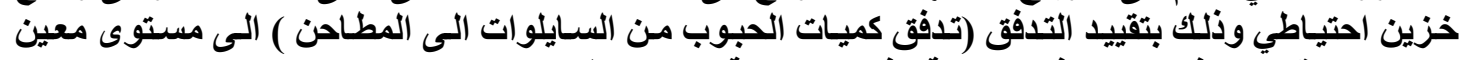

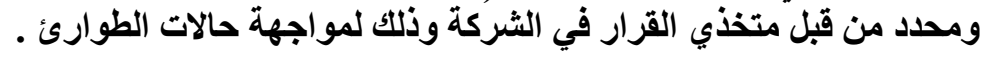

(4) (4) الجانب النظري

[9][3][1-4] البرهجة الفطية الشكلة النقل

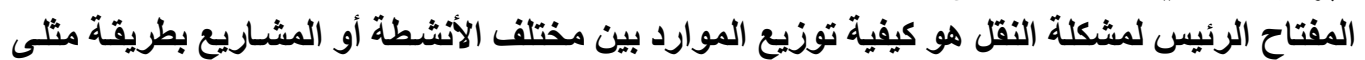

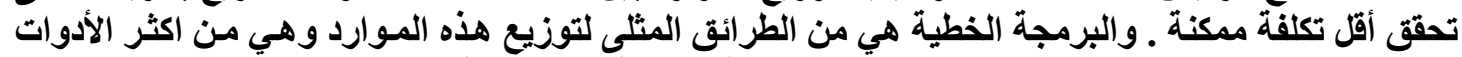

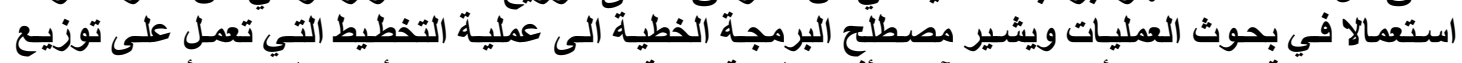

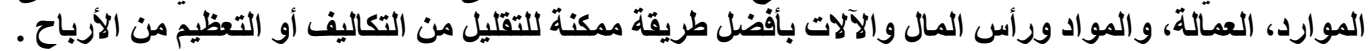

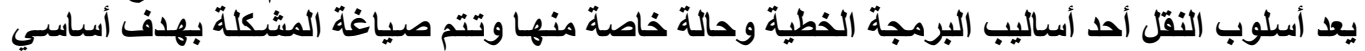
هو تحديد عدد الوحدات المنقولة من المصادر الى مراكز الطلب بأقل كلقة . 


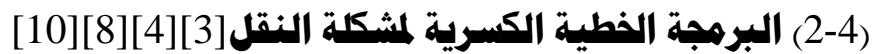

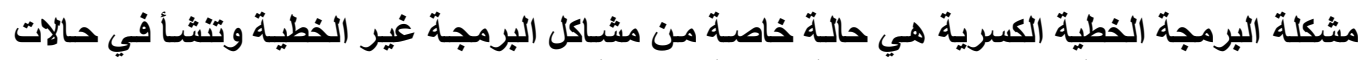

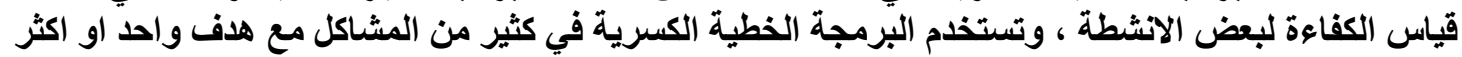

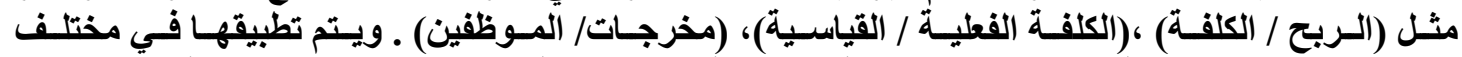

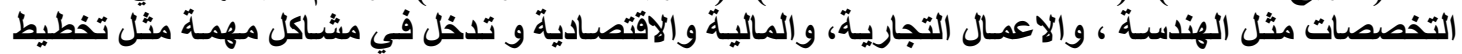

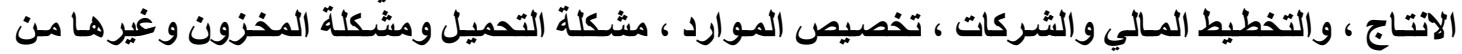

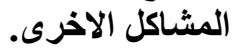

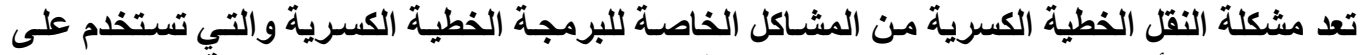

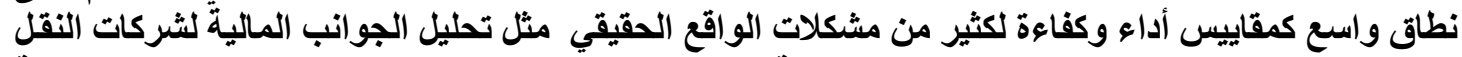

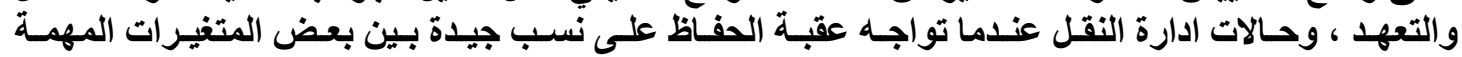

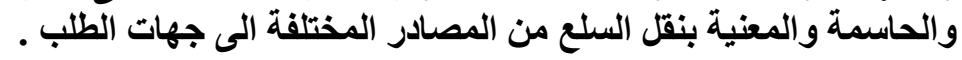

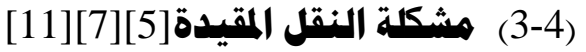

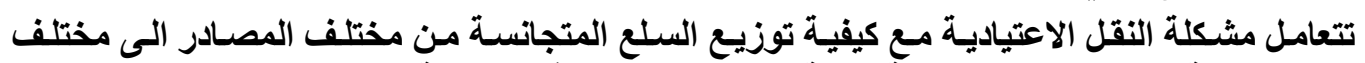

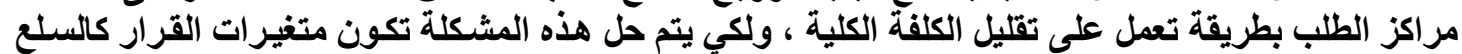

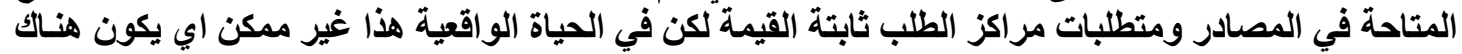

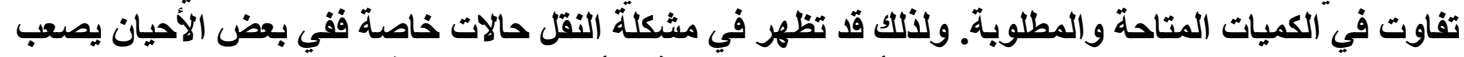

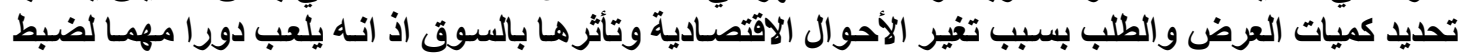

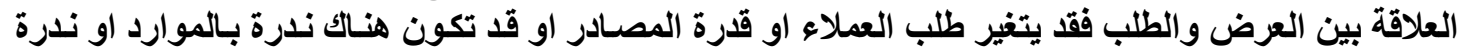

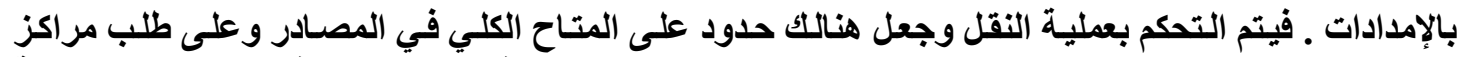

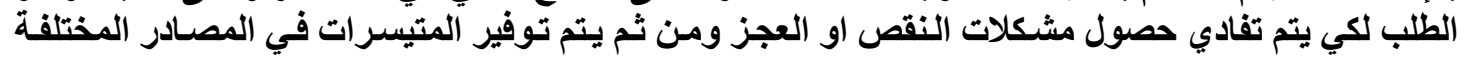

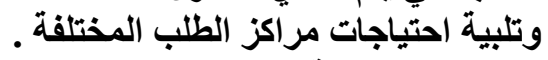

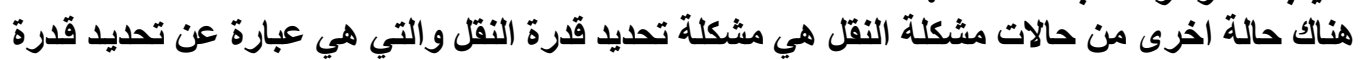

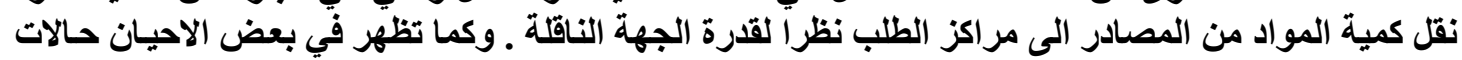

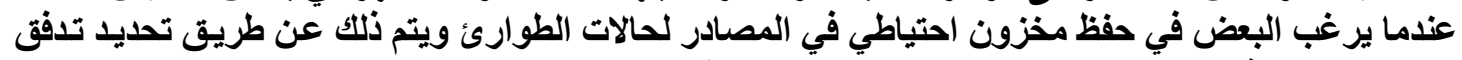

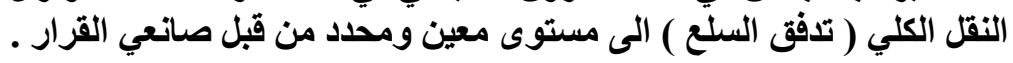

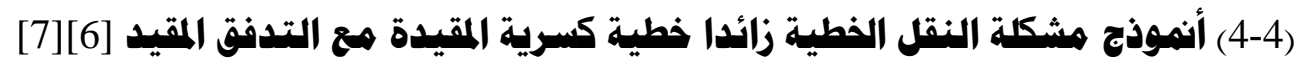

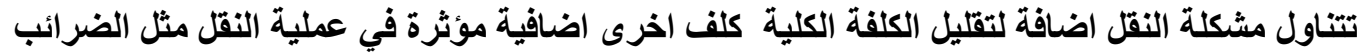

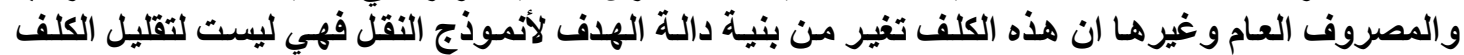

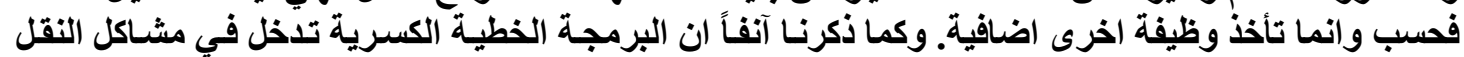

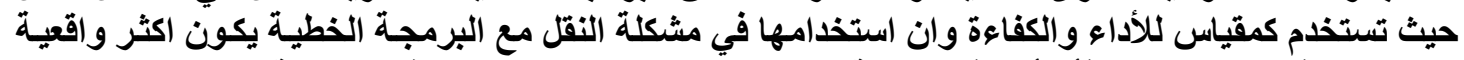

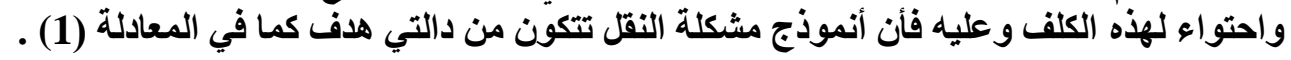

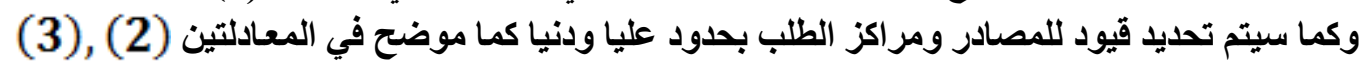

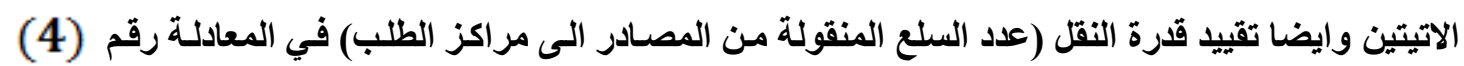

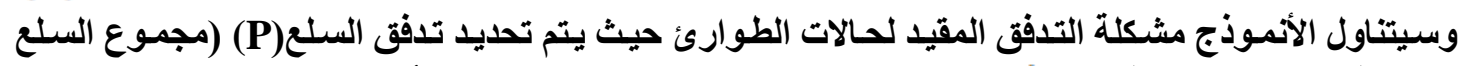

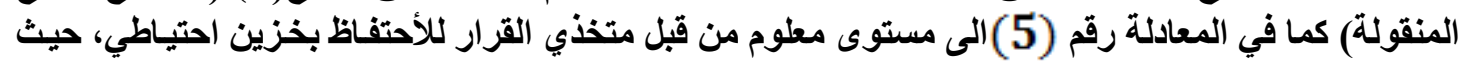

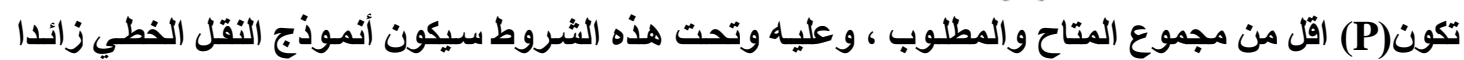
الخطي الكسري مع التدفق المقيد كالآتي : 
P1:minZ $=\sum_{i \in I} \sum_{j \in J} c i j x i j+\frac{\sum_{i \in I} \sum_{j \in J} t i j x i j}{\sum_{i \in I} \Sigma_{j \in J} r i j x i j}$

subject to:

$a i \leq x i j \leq A i, \quad \forall i \in I$

$b_{j} \leq x_{i j} \leq \boldsymbol{B}_{j}, \quad \forall \boldsymbol{j} \in \boldsymbol{J}$

(4) $\quad$ lij $\leq x i j \leq u i j$ and integers $\forall i \in I, j \in J$

$\sum_{i \in I} \sum_{j \in J} x i j=p$

$p<\min \left[\sum_{i \in I} A i, \sum_{j \in J} B j\right]$

$I=\{1,2, \ldots \ldots, m\} \quad J=\{1,2, \ldots \ldots, n\}$

j = cij j rij

j =tij

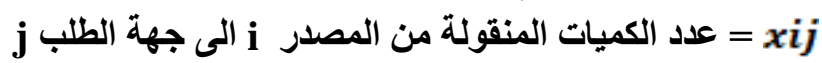

الحدود على الكميات المتاحة في المصدر، = aiAi

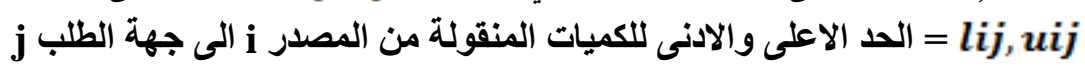

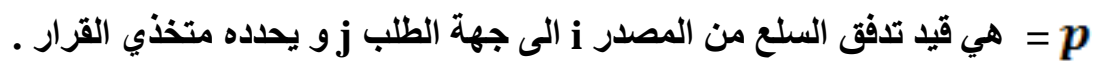

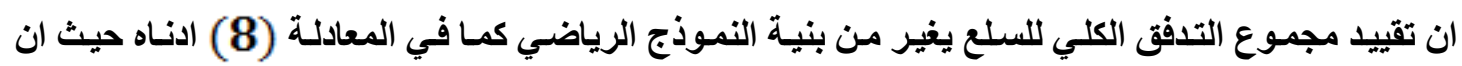

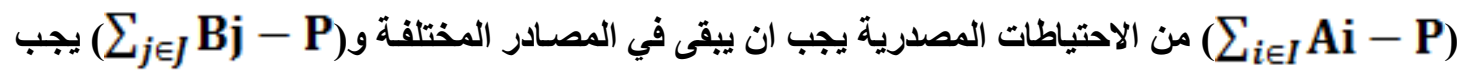

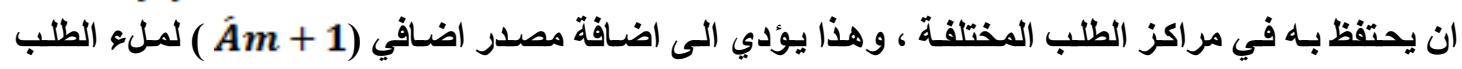

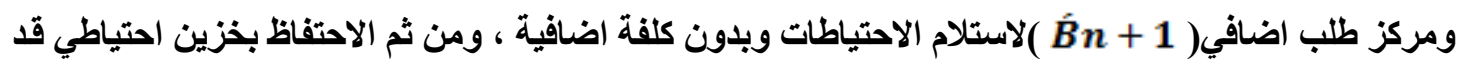

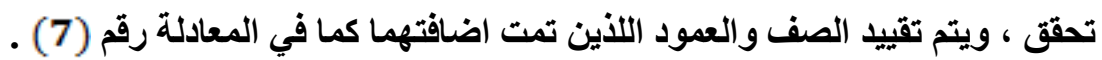
الأنموذج الاتي أنموذج نقل غير متوازن ، ويتم موازنة الأنموذج السابق وحله بيناء أنموذج مكافئ وكالآتي:

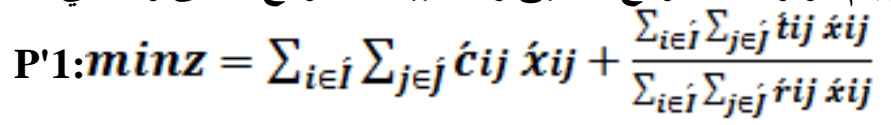

subject to:

$$
\begin{aligned}
& \sum_{j \in j} \hat{x} i j=\hat{A} i \quad \forall i \in I, \quad \sum_{i \in \hat{I}} \hat{x} i j=\hat{B} j \quad \forall j \in f \\
& 0 \leq \dot{x} m+1, j \leq B j-b j \quad \forall j \in J \\
& 0 \leq x i, n+1 \leq A i-a i \quad \forall i \in I \\
& l i j \leq x i j \leq u i j \quad \forall(i, j) \in I \times J \quad \zeta x m+1, n+1=0 \\
& \hat{A} i=A i \quad \forall i \in I, \hat{B} j=B j \quad \forall j \in J \\
& \hat{A} m+1=\sum_{j \in J} B j-P \\
& \hat{B} n+1=\sum_{i \in I} A i-P \\
& { }^{\prime} i j=c i j,{ }^{\prime} i j=r i j, t i j=t i j \\
& \hat{c} m+1, j=\hat{c} i, n+1=\hat{r} m+1, j=\hat{r} i, n+1=\hat{t} m+1, j=\hat{t} i j, n+1=0
\end{aligned}
$$


$M$ is large positive number $c m+1, n+1=r m+1, n+1=\hat{t} m+1, n+1=M$ $\hat{I}=\{1,2, \ldots \ldots, m, m+1\} \quad, \hat{J}=\{1,2, \ldots \ldots, n, n+1\}$.

j كلفة نقا

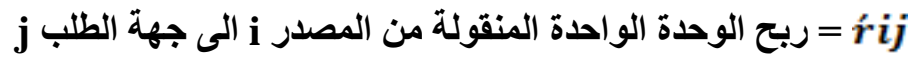

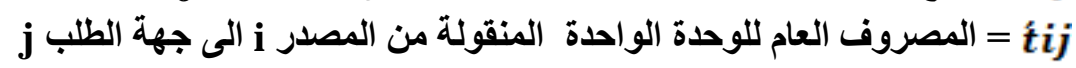
j ع = xij

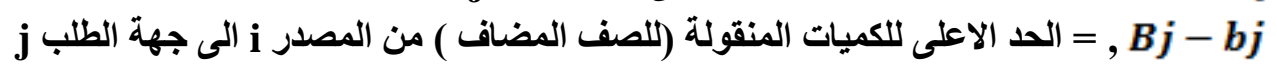

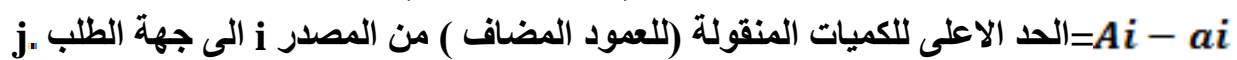
$\hat{I}=\{1,2, \ldots \ldots, m, m+1\} \quad \hat{J}=\{1,2, \ldots \ldots, n, n+1\}$.

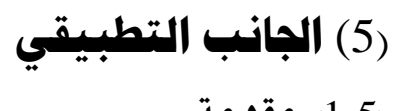

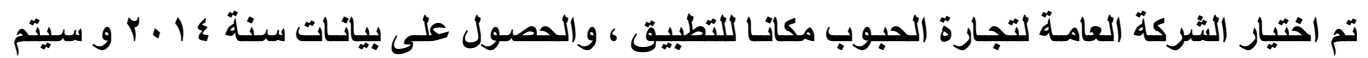

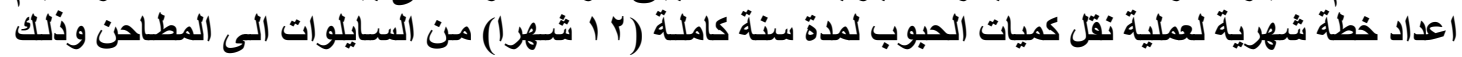

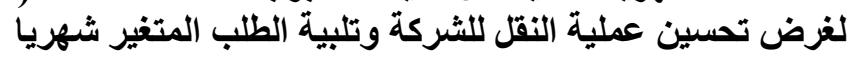

الأنموذج الرئيس هو أنموذج رياضي : الأمي لمشكلة النقل والذي يتألف من دالتي هدف خطية والمتمثلة بكلفة النقل

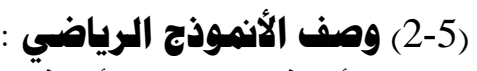

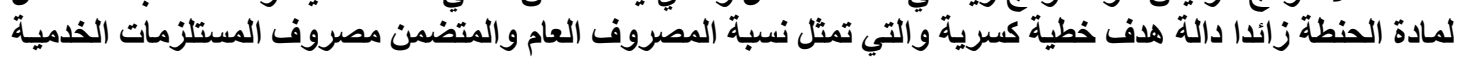

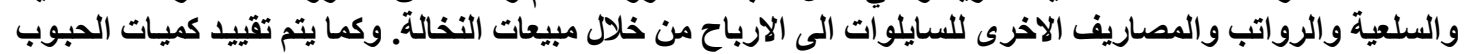

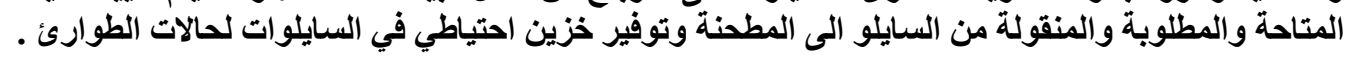

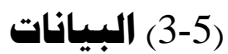

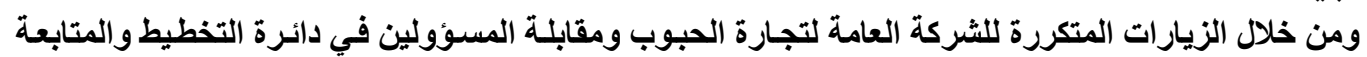

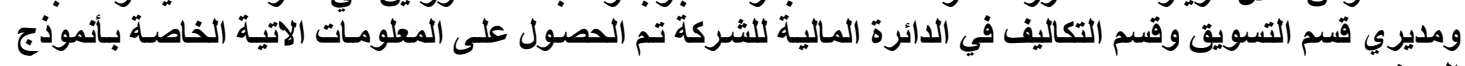

البحث: : البري :

ا.كلف النقل' : يبين الجدول رقم (1) كلفة نقل الطن الواحد من الحبوب .

\begin{tabular}{|c|c|c|c|c|c|c|c|c|c|c|c|}
\hline سان بني & ضاريــان & الدورة & الرصافة & التاجي & مطحنة/سايلو & سعدان بــي & ضاريــان & الدورة & الرصافة & التاجي & مطحنة/سايلو \\
\hline 3.78 & 4.98 & 2.52 & 0.06 & 4.26 & بغداد & 3.3 & 3.54 & 1.14 & 1.56 & 3 & النصر \\
\hline 3.3 & 3.42 & 1.14 & 1.56 & 3 & الراضي & 2.4 & 3.54 & 1.08 & 1.56 & 3 & النهرين \\
\hline 2.4 & 3.42 & 1.08 & 1.56 & 3 & الهلال & 3.78 & 4.92 & 2.52 & 0.12 & 4.26 & الصباح \\
\hline 4.68 & 4.92 & 2.46 & 0.12 & 4.26 & الراية & 1.56 & 3.42 & 1.44 & 2.58 & 2.7 & السرور/العراق \\
\hline 3.12 & 4.32 & 1.86 & 2.16 & 3.6 & الأسراء & 1.56 & 3.42 & 1.8 & 2.4 & 2.7 & العزاوي \\
\hline 3.12 & 4.26 & 1.8 & 1.8 & 3.6 & حطين & 1.56 & 3.42 & 1.44 & 2.58 & 2.7 & شط العرب \\
\hline 1.56 & 3.42 & 1.8 & 2.7 & 2.7 & الكوثر & 2.4 & 3.42 & 1.08 & 1.56 & 3 & خيرات الزوراء \\
\hline 3.78 & 4.98 & 2.52 & 0.06 & 4.26 & الناصر & 2.4 & 2.1 & 0.3 & 2.28 & 2.4 & العزة/المهلدي \\
\hline 2.4 & 3.42 & 1.08 & 1.56 & 3 & 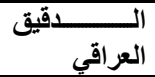 & 1.68 & 3.54 & 1.44 & 2.4 & 2.7 & الهادي \\
\hline
\end{tabular}




\begin{tabular}{|c|c|c|c|c|c|c|c|c|c|c|c|}
\hline 3.12 & 2.64 & 0.72 & 3 & 2.88 & الأيمان & 2.16 & 1.98 & 1.02 & 2.76 & 1.62 & العطيفية \\
\hline 3.96 & 3.06 & 1.44 & 4.14 & 3.72 & الفجر & 3.18 & 3.54 & 2.52 & 4.14 & 0.12 & الحلبي \\
\hline 3.12 & 2.76 & 0.6 & 3 & 2.88 & الذهب الاسود & 3.96 & 0.78 & 1.5 & 4.86 & 3.12 & الفلاح \\
\hline 3.96 & 3.06 & 1.44 & 4.14 & 3.72 & الكرخ & 4.62 & 0.06 & 2.76 & 4.92 & & الخنساء \\
\hline 3.12 & 2.76 & 0.6 & 3 & 2.88 & الأهرام & 1.74 & 2.94 & 1.8 & 4.14 & 1.8 & الورد \\
\hline 3.12 & 2.64 & 0.72 & 3.24 & 2.88 & خالد & 4.32 & 0.12 & 2.76 & 4.98 & 3.54 & الرياض \\
\hline 3.12 & 2.76 & 0.72 & 3 & 2.88 & الوادي/الامين & 2.64 & 1.62 & 1.26 & 3.84 & 1.44 & النور \\
\hline 3.12 & 2.76 & 0.72 & 3.24 & 2.88 & النسر & 1.92 & 2.16 & 1.02 & 2.64 & 1.8 & السلامة \\
\hline 2.52 & 1.62 & 1.26 & 3.84 & 1.44 & الثرقي & 1.92 & 2.16 & 1.02 & 2.64 & 1.8 & المنصور \\
\hline 2.7 & 2.76 & 0.06 & 2.46 & 2.52 & الدورة الحكومية & 2.16 & 2.16 & 1.02 & 2.76 & 1.8 & الشرق \\
\hline 3.18 & 3.54 & 2.52 & 4.26 & 0.06 & التاجي الحكومية & 1.68 & 2.52 & 1.5 & 2.64 & 1.74 & الجميلة \\
\hline 0.06 & 4.32 & 2.7 & 3.78 & 3.18 & المقداد الحكومية & 4.32 & 0.18 & 2.58 & 4.98 & 3.54 & الزهاء \\
\hline 3.78 & 4.92 & 2.46 & 0.06 & 4.14 & الرصافة|الحكومية & 4.32 & 0.12 & 2.58 & 4.92 & 3.54 & المنورة المدينــــة \\
\hline
\end{tabular}

ץ. ربح الطن الواحد هن الحنطة : الثركة العامة لتجارة الحبوب هي مؤسسة خدمية ومن ثم تكون ارباحها

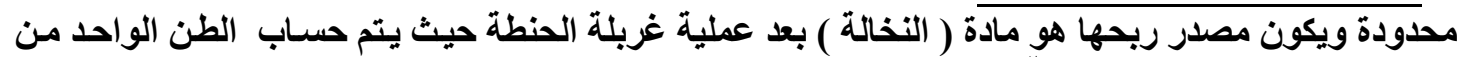

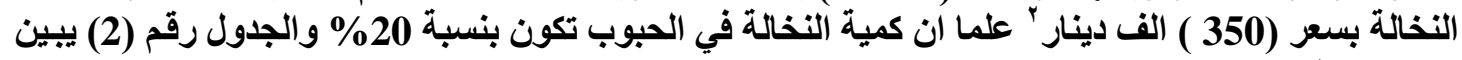

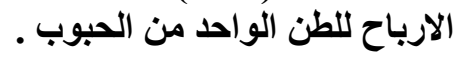

\begin{tabular}{|c|c|c|c|c|c|c|c|c|c|c|c|}
\hline خان بني & ضاري & الدورة & الرصافة & التاجي & مطاحن/سايلو & خان بني & ضان & الاورة & الرصافة & التاجي & مطاحن/سايلو \\
\hline 9.1 & 9.1 & 9.1 & 9.1 & 9.1 & الورد & 9.1 & 9.1 & 9.1 & 9.1 & 9.1 & النصر \\
\hline 9.1 & 9.1 & 9.1 & 9.1 & 9.1 & الرياض & 9.1 & 9.1 & 9.1 & 9.1 & 9.1 & النهرين \\
\hline 9.1 & 9.1 & 9.1 & 9.1 & 9.1 & النور & 9.1 & 9.1 & 9.1 & 9.1 & 9.1 & الصباح \\
\hline 9.1 & 9.1 & 9.1 & 9.1 & 9.1 & السلامة & 9.1 & 9.1 & 9.1 & 9.1 & 9.1 & السرور/الكراق \\
\hline 9.1 & 9.1 & 9.1 & 9.1 & 9.1 & المنصور & 9.1 & 9.1 & 9.1 & 9.1 & 9.1 & العزاوي \\
\hline 9.1 & 9.1 & 9.1 & 9.1 & 9.1 & الثرق & 9.1 & 9.1 & 9.1 & 9.1 & 9.1 & شط العرب \\
\hline 9.1 & 9.1 & 9.1 & 9.1 & 9.1 & جميلة & 9.1 & 9.1 & 9.1 & 9.1 & 9.1 & خيرات الزورا \\
\hline 9.1 & 9.1 & 9.1 & 9.1 & 9.1 & الزهاء & 9.1 & 9.1 & 9.1 & 9.1 & 9.1 & العزة/المهاي \\
\hline 9.1 & 9.1 & 9.1 & 9.1 & 9.1 & المدينة المنورة & 9.1 & 9.1 & 9.1 & 9.1 & 9.1 & اللهادي \\
\hline 9.1 & 9.1 & 9.1 & 9.1 & 9.1 & الايمان & 9.1 & 9.1 & 9.1 & 9.1 & 9.1 & بغداد \\
\hline 9.1 & 9.1 & 9.1 & 9.1 & 9.1 & الفجر & 9.1 & 9.1 & 9.1 & 9.1 & 9.1 & الر اضي \\
\hline 9.1 & 9.1 & 9.1 & 9.1 & 9.1 & الأهب الاسود & 9.1 & 9.1 & 9.1 & 9.1 & 9.1 & الهلال \\
\hline 9.1 & 9.1 & 9.1 & 9.1 & 9.1 & الكرخ & 9.1 & 9.1 & 9.1 & 9.1 & 9.1 & الراية \\
\hline 9.1 & 9.1 & 9.1 & 9.1 & 9.1 & الاهرام & 9.1 & 9.1 & 9.1 & 9.1 & 9.1 & الاسراء \\
\hline 9.1 & 9.1 & 9.1 & 9.1 & 9.1 & خالد & 9.1 & 9.1 & 9.1 & 9.1 & 9.1 & حطين \\
\hline 9.1 & 9.1 & 9.1 & 9.1 & 9.1 & الو ادي الامين & 9.1 & 9.1 & 9.1 & 9.1 & 9.1 & الكوثز \\
\hline 9.1 & 9.1 & 9.1 & 9.1 & 9.1 & النسر & 9.1 & 9.1 & 9.1 & 9.1 & 9.1 & الناصر \\
\hline 9.1 & 9.1 & 9.1 & 9.1 & 9.1 & الثرقي & 9.1 & 9.1 & 9.1 & 9.1 & 9.1 & الدقيق العراقي \\
\hline 70 & 70 & 70 & 70 & 70 & الاورة الحكومية & 9.1 & 9.1 & 9.1 & 9.1 & 9.1 & العطيفية \\
\hline 70 & 70 & 70 & 70 & 70 & التاجي الحكومية & 9.1 & 9.1 & 9.1 & 9.1 & 9.1 & الحلبي \\
\hline 70 & 70 & 70 & 70 & 70 & المقداد الحكومية & 9.1 & 9.1 & 9.1 & 9.1 & 9.1 & الفلاح \\
\hline 70 & 70 & 70 & 70 & 70 & الرصافة الحكومية & 9.1 & 9.1 & 9.1 & 9.1 & 9.1 & الخنساء \\
\hline
\end{tabular}

^ يتم حساب الارباح بالنسبة للمطاحن الاهلية بنسبة 13\% . 


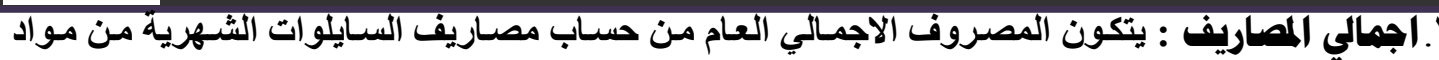
اولية و حساب المستلزمات السلعية من زيوت ومياتئل ومياه وكهرباء وحساب المستلزمات الخدمية من صيانة مباني وآلات وصيانة وسائط نقل وانتقال ويأتي . جذول رقم (3) يبين المصروف العام

\begin{tabular}{|c|c|c|c|c|c|c|c|c|c|c|c|}
\hline سبــــــ & ضـاريـان & الاورة & الرصافة & التاجي & مطاحن/سايلو & سنـــــان & ضاريـان & الاورة & الرصافة & التاجي & مطاحن/سايلو \\
\hline 5.7 & 2.4 & 9.9 & 3.989 & 12 & الورد & 5.7 & 2.4 & 9.9 & 3.989 & 12 & النصر \\
\hline 5.7 & 2.4 & 9.9 & 3.989 & 12 & الرياض & 5.7 & 2.4 & 9.9 & 3.989 & 12 & النهرين \\
\hline 5.7 & 2.4 & 9.9 & 3.989 & 12 & النور & 5.7 & 2.4 & 9.9 & 3.989 & 12 & الصباح \\
\hline 5.7 & 2.4 & 9.9 & 3.989 & 12 & السلامة & 5.7 & 2.4 & 9.9 & 3.989 & $\overline{12}$ & السرور/العراق \\
\hline 5.7 & 2.4 & 9.9 & 3.989 & 12 & المنصور & 5.7 & 2.4 & 9.9 & 3.989 & 12 & العزاوي \\
\hline 5.7 & 2.4 & 9.9 & 3.989 & 12 & الثرق & 5.7 & 2.4 & 9.9 & $\mathbf{3 . 9 8 9}$ & 12 & شط العرب \\
\hline 5.7 & 2.4 & 9.9 & 3.989 & 12 & جميلة & 5.7 & 2.4 & 9.9 & $\mathbf{3 . 9 8 9}$ & 12 & خيرات الزورا \\
\hline 5.7 & 2.4 & 9.9 & 3.989 & 12 & الزهاء & 5.7 & 2.4 & 9.9 & 3.989 & 12 & العزة/المهدي \\
\hline 5.7 & 2.4 & 9.9 & 3.989 & 12 & المدينة المنورة & 5.7 & 2.4 & 9.9 & 3.989 & 12 & الهادي \\
\hline 5.7 & 2.4 & 9.9 & 3.989 & 12 & الايمان & 5.7 & 2.4 & 9.9 & $\mathbf{3 . 9 8 9}$ & 12 & 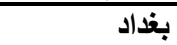 \\
\hline 5.7 & 2.4 & 9.9 & 3.989 & $\overline{12}$ & الفجر & 5.7 & 2.4 & 9.9 & $\mathbf{3 . 9 8 9}$ & 12 & الراضي \\
\hline 5.7 & 2.4 & 9.9 & 3.989 & 12 & الذهب الاسود & 5.7 & 2.4 & 9.9 & $\mathbf{3 . 9 8 9}$ & 12 & الهلال \\
\hline 5.7 & 2.4 & 9.9 & 3.989 & 12 & الكرخ إخ & 5.7 & 2.4 & 9.9 & 3.989 & 12 & الراية \\
\hline 5.7 & 2.4 & 9.9 & 3.989 & 12 & الاهرام & 5.7 & 2.4 & 9.9 & 3.989 & 12 & |لاسراء \\
\hline 5.7 & 2.4 & 9.9 & 3.989 & 12 & خالد & 5.7 & 2.4 & 9.9 & 3.989 & 12 & حطين \\
\hline 5.7 & 2.4 & 9.9 & 3.989 & 12 & الوادي الامين & 5.7 & 2.4 & 9.9 & 3.989 & 12 & الكوثر \\
\hline 5.7 & 2.4 & 9.9 & 3.989 & 12 & النسر & 5.7 & 2.4 & 9.9 & 3.989 & 12 & الناصر \\
\hline 5.7 & 2.4 & 9.9 & 3.989 & 12 & الثرقي & 5.7 & 2.4 & 9.9 & 3.989 & 12 & الاقيق العراقي \\
\hline 5.7 & 2.4 & 9.9 & 3.989 & 12 & اللاورة الحكومية & 5.7 & 2.4 & 9.9 & 3.989 & 12 & العطيفية \\
\hline 5.7 & 2.4 & 9.9 & 3.989 & 12 & التاجي الحكومية & 5.7 & 2.4 & 9.9 & 3.989 & 12 & الحلبي \\
\hline 5.7 & 2.4 & 9.9 & 3.989 & 12 & المقداد الحكومية & 5.7 & 2.4 & 9.9 & 3.989 & 12 & الفلاح \\
\hline 5.7 & 2.4 & 9.9 & 3.989 & 12 & الرصافة|/لحكومية & 5.7 & 2.4 & 9.9 & 3.989 & 12 & الخنساء \\
\hline
\end{tabular}

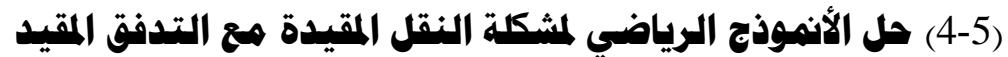

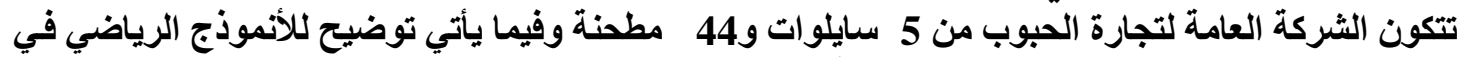
ظل البيانات المذكورة مسبقا حيث تكون المعادلة رقم (1) كالاتي : P1: Minz $=\sum_{i \in I} \sum_{j \in J} \operatorname{cij} x i j+\frac{\sum_{i \in I} \Sigma_{j \in J} t i j x i j}{\sum_{i \in I} \Sigma_{j \in I} r i j x i j}$

$$
\sum_{i \in I} \sum_{j \in I} r i j x i j>0
$$

$\mathrm{I}=\{1, \ldots \ldots, 5\}$ $\mathrm{J}=\{1,2,3, \ldots \ldots \ldots \ldots \ldots . . ., 44\}$

قيد الكميات المتاحة في السايلوات i $a i \leq \sum_{j=1}^{44} x i j \leq A i \quad i \in \mathrm{I}=\{1, \ldots . . ., 5\}$

$$
b_{j} \leq \sum_{i=1}^{5} x i j \leq B j \quad j \in J=\{1,2,3, \ldots \ldots \ldots, 44\}
$$

قيد الكميات المطلوية في المطاحن 


$$
\begin{aligned}
& \sum_{i=1}^{5} \sum_{j=1}^{44} x i j=P \\
& \mathrm{P}\left(<\min \left(\sum_{i=1}^{5} A i, \sum_{j=1}^{44} B j\right)\right) \\
& \quad \mathrm{P}(<\min (130025,61359))
\end{aligned}
$$

قيد الكميات المنقولة من السايلوi الى المطنة ان (4عادلة (4)ر)

$l i j \leq X i j \leq u i j$

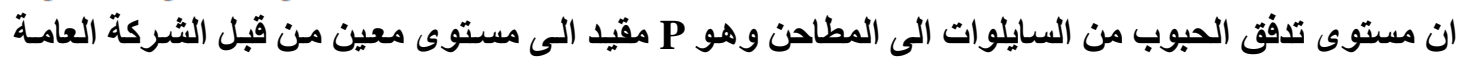
$P=\mathbf{5 2 1 6 5}$ لتجارة الحبوب لضمان خزين احتياطي يكفي لتلبية طلب شهر ونصف المف ونف تقريبا حيث :

$$
\text { ومن ثم فأن الخزين الاحتياطي وبحسب المعادلة (8) والذي يمثل B45 يبلغ }
$$

\section{$B 45=77860$}

$$
A 6=9194
$$

وايضا حسب المعادلة (8) فأن

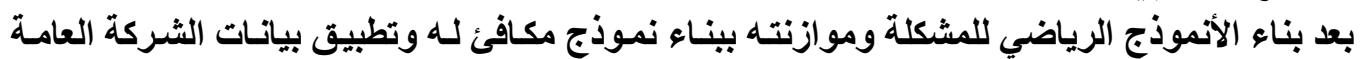

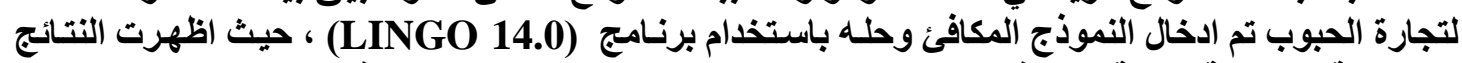

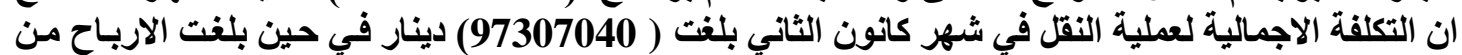

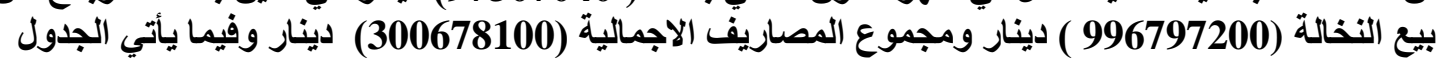

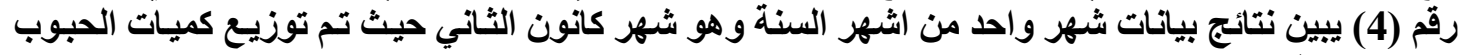
على ؛ ؛ مطحنه من ه هايلوات. جلول رقم (4) يبين نتائج الحل وتوزيع كميات الحبوب (بالطن)على المطاحن لشهر كانون الثاني

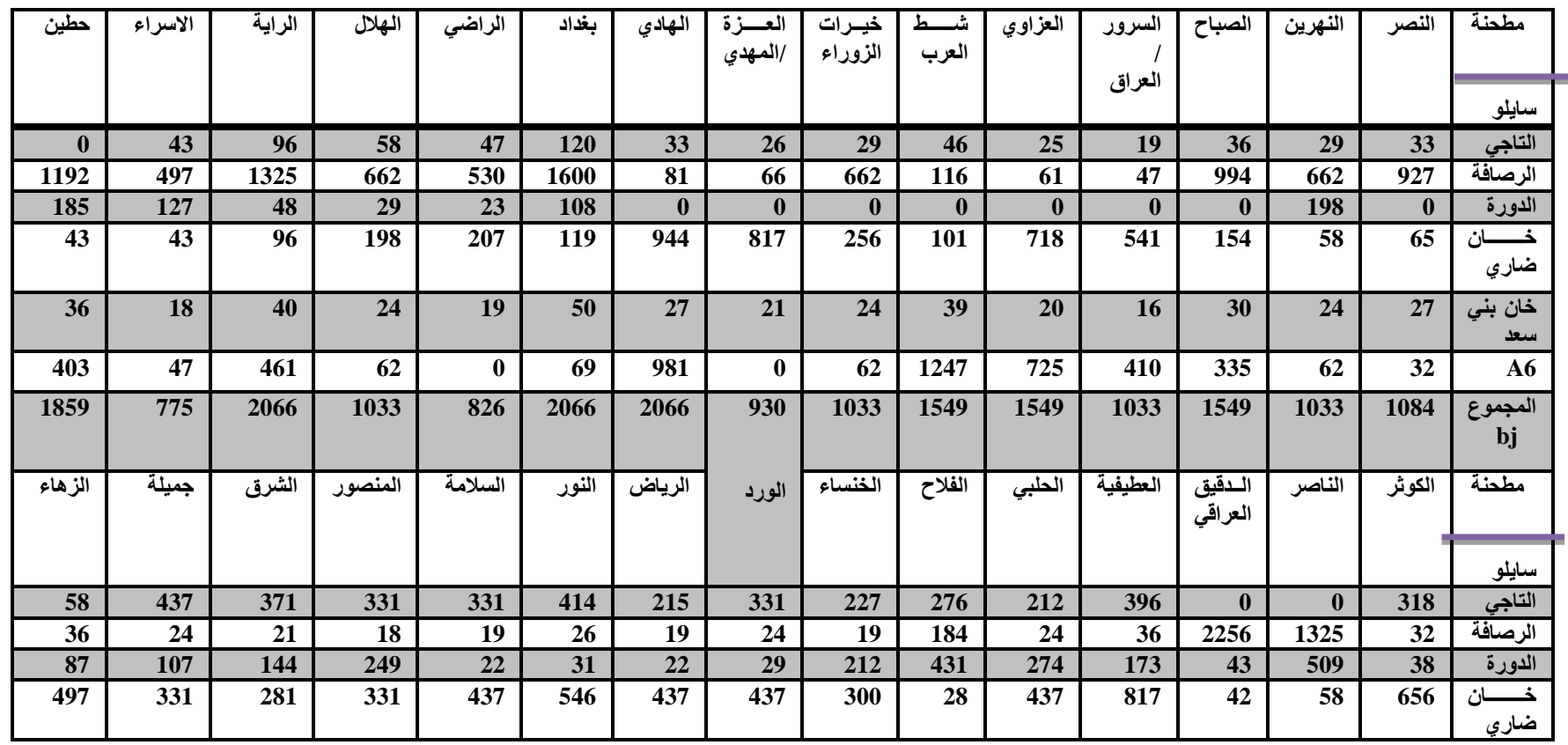


بناء انموذجِ رياضحي لمشكلة النقل فهي ظلا قيود ريناميكية الطلب مع تطبيقا عمليا

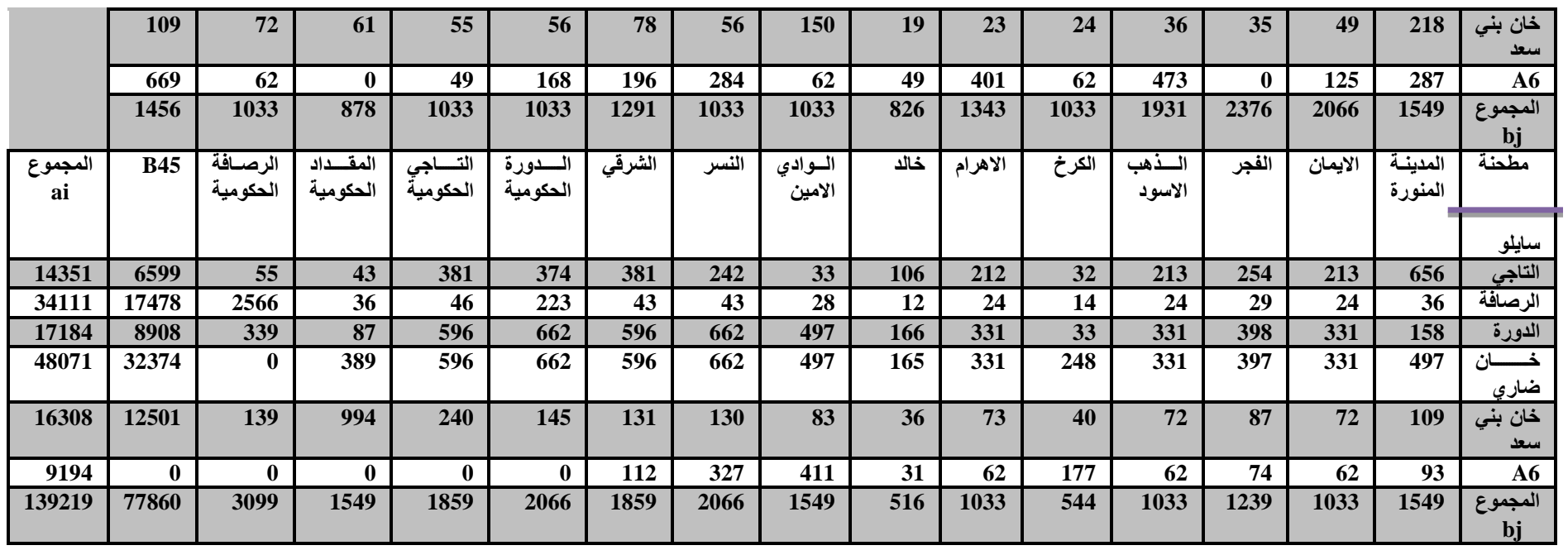

بعد تطبيق بيانات الاشهر الباقية وظهور نتائجها تم اعداد الجدول رقم (5) لبيـان الفرق الواضـح للكلفة

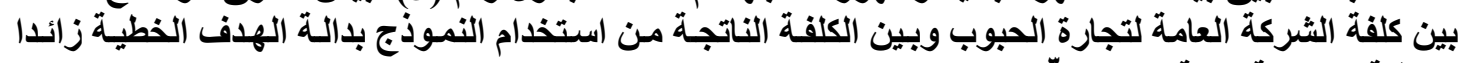

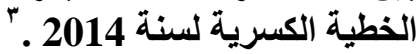
جدول رقم (5) يوضح الكلفة الكلية للثركة و الكلفة الكلية للنموذج بدالة هدف خطية زائدا خطية كسرية

\begin{tabular}{|c|c|c|}
\hline أكلفة الكلية للنموذج & الكلفة الكلية للشركة & \\
\hline 97307.04 & 128451.8 & كانون r \\
\hline 97282.98 & 113800.1 & شباط \\
\hline 97334.52 & 109335.2 & آذار \\
\hline 97199.46 & 161271 & نيسـان \\
\hline 97390.92 & 100608.1 & مايس \\
\hline 101591.2 & 104538.1 & حزيران \\
\hline 102298.4 & 106566.72 & تموز \\
\hline 94613.04 & 99117.54 & آب \\
\hline 96961.56 & 97882.66 & ايلول \\
\hline 96532.62 & 107394.2 & تثرين 1 \\
\hline 97293.12 & 122137.2 & تشرينr \\
\hline 98873.46 & 123694.4 & كانون \\
\hline
\end{tabular}

ويبين الجدول رقم (6) المصروف الكلي العام للثركة والمصروف العام الكلي للنموذج لسنة 2014 حيث يكون واضحا مدى تقليل النموذج للمصروف المصروف ألعام . 
بناء أنموزح رياضي لمشكلة النقلا فحي ظلا قيود ريناميكية الطلب مع تطبيقا عمليي

جدول رقم (6) يوضح المصروف العام للثركة وللأنموذج لسنة كاملة

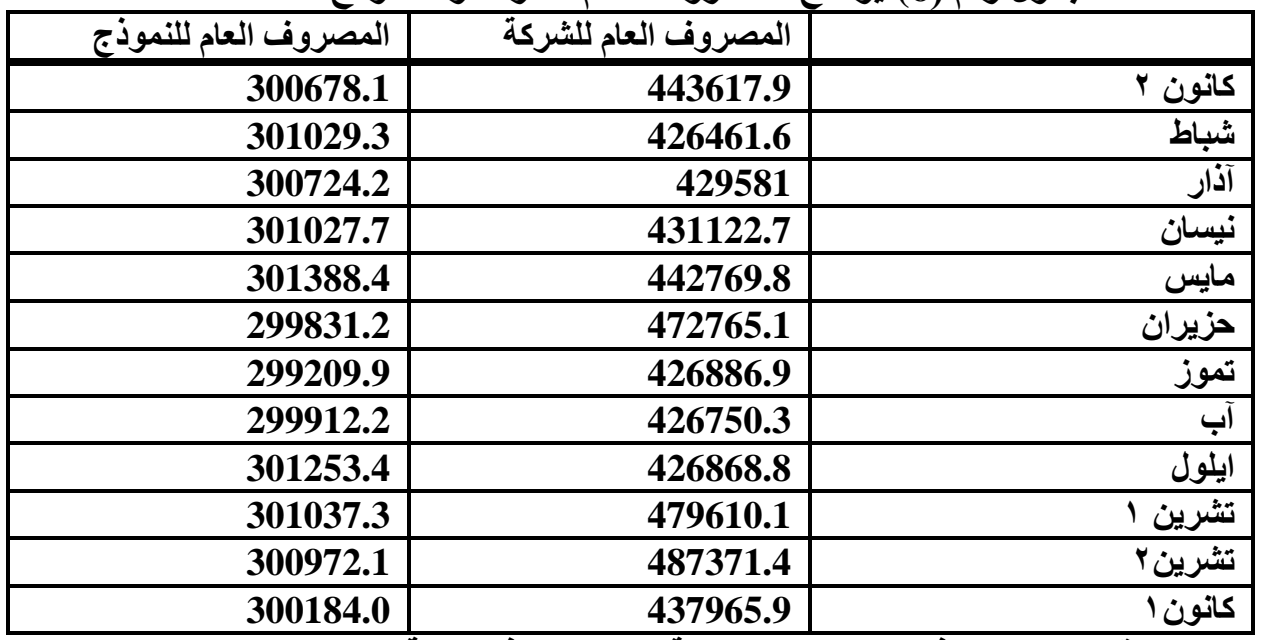

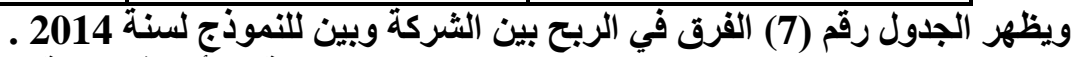
جدول رقم (7) يوضح الربح للشركة وللأنموذج لسنة كاملة الرئة

\begin{tabular}{|c|c|c|}
\hline ربح الأنموذج & ربح الشركة & \\
\hline 996797.2 & 925018.5 & كانون r \\
\hline 1019269 & 974778 & شباط \\
\hline $\mathbf{1 0 1 7 6 8 6}$ & 945464.1 & آذار \\
\hline 1015737 & 949321.8 & نيسان \\
\hline 1046187 & 934791.9 & مايس \\
\hline 1015372 & 988895.6 & حزيران \\
\hline 1123652 & 867090 & تموز \\
\hline 965311.9 & 895743.1 & آب \\
\hline 1026821 & 875350 & ايلول \\
\hline 1019696 & 962079.3 & تشرين 1 \\
\hline 1044482 & 923821.5 & تشرين \\
\hline 1060742 & 947175.6 & كانونا \\
\hline
\end{tabular}




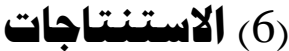

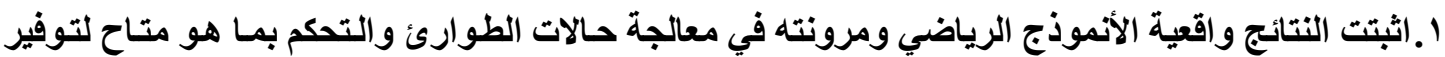

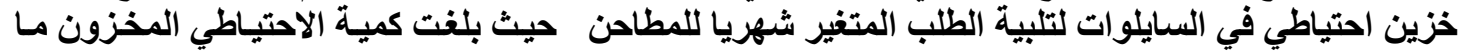

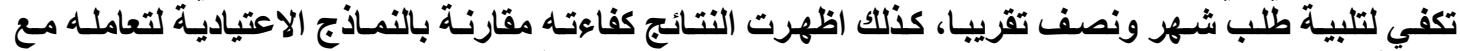

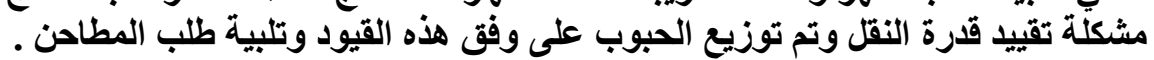

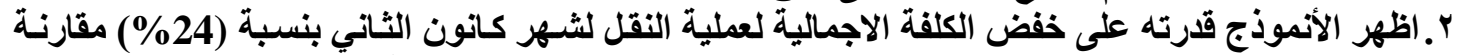

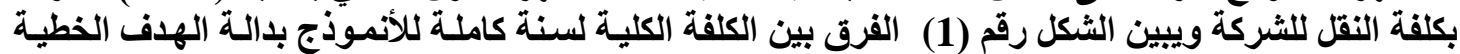

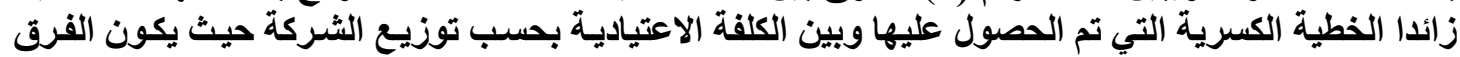

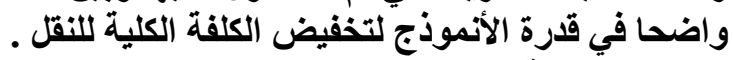

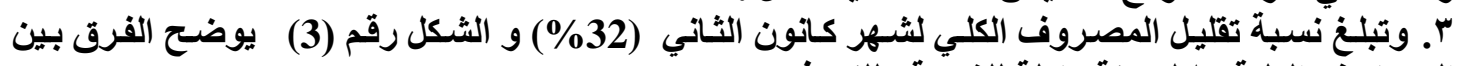

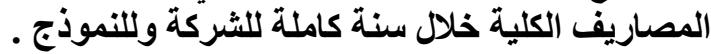

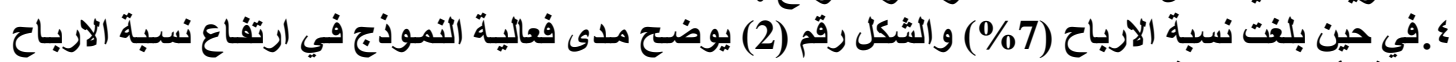

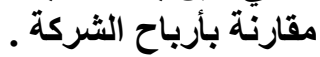

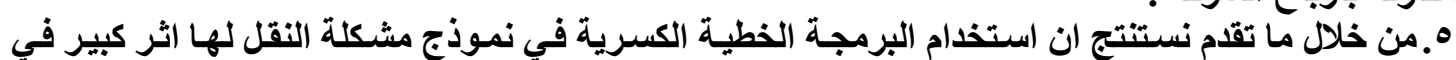

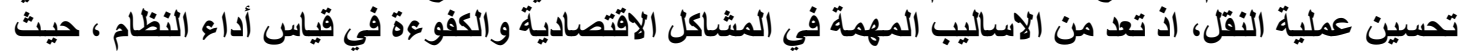

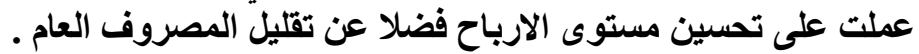
الثكل رقم (1) يبين الفرق بين الكلفة الإجمالية للشركة ولثيل الكلفة الخطية زائدا الخطية الكسرية للأنموذج

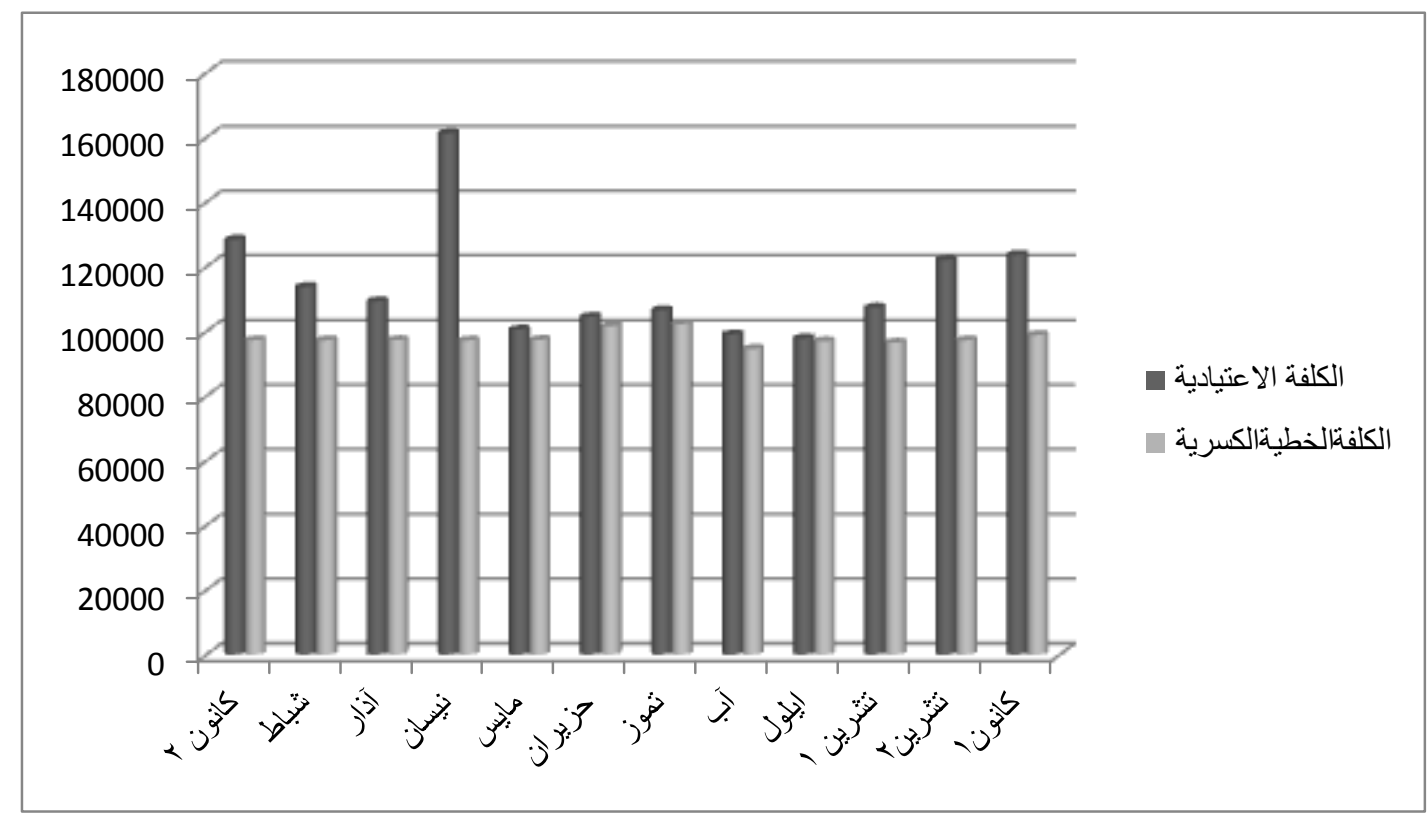

$$
\text { الثكل رقم (2) يوضح الربح للشركة والربح للنموذج }
$$


بناء أنموزحِ رياضي لمشكلة النقل فحي ظلا قيور ريناميكية الطلب مع تطبيقا عمليا

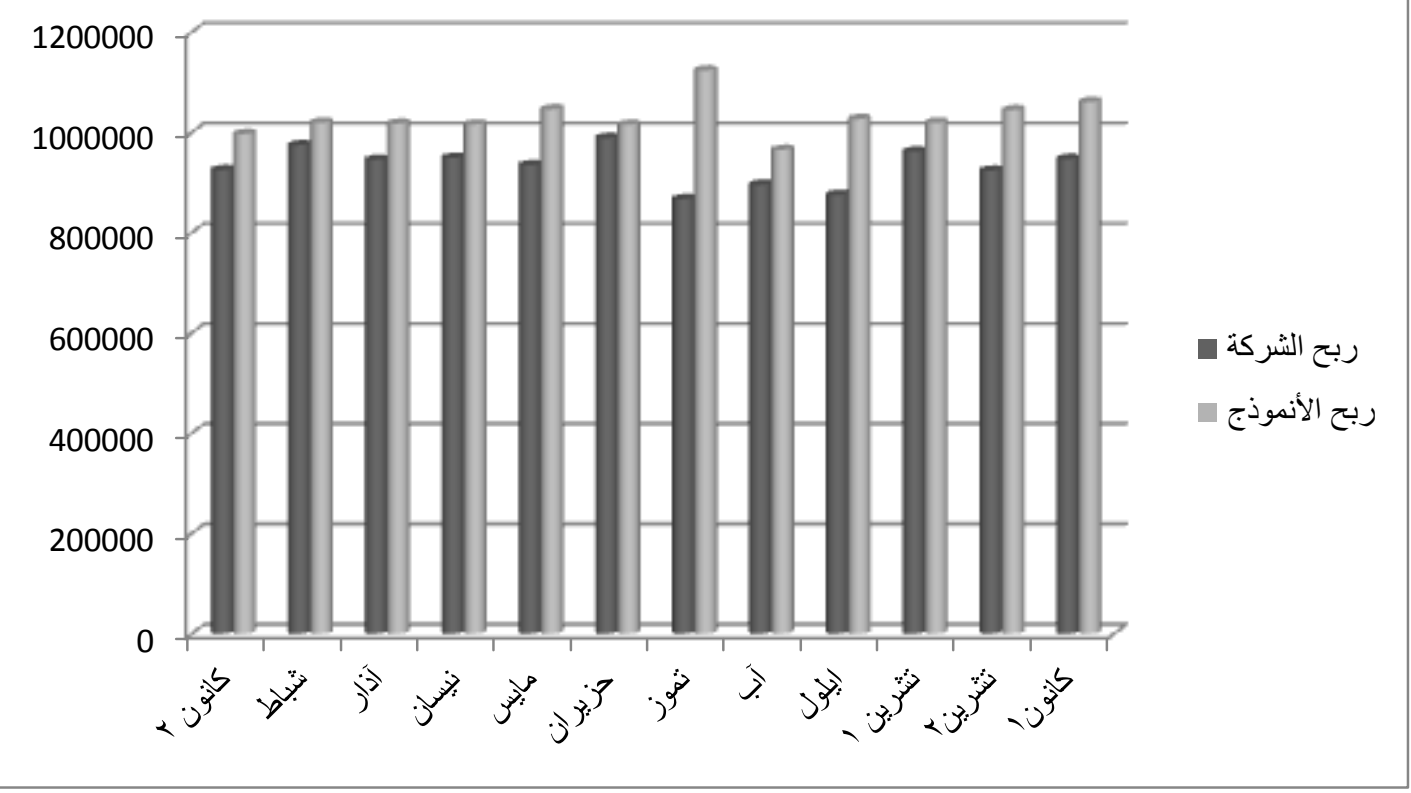




$$
\text { الثكل رقم (3) يبين المصروف العام للشركة وللنموذج }
$$

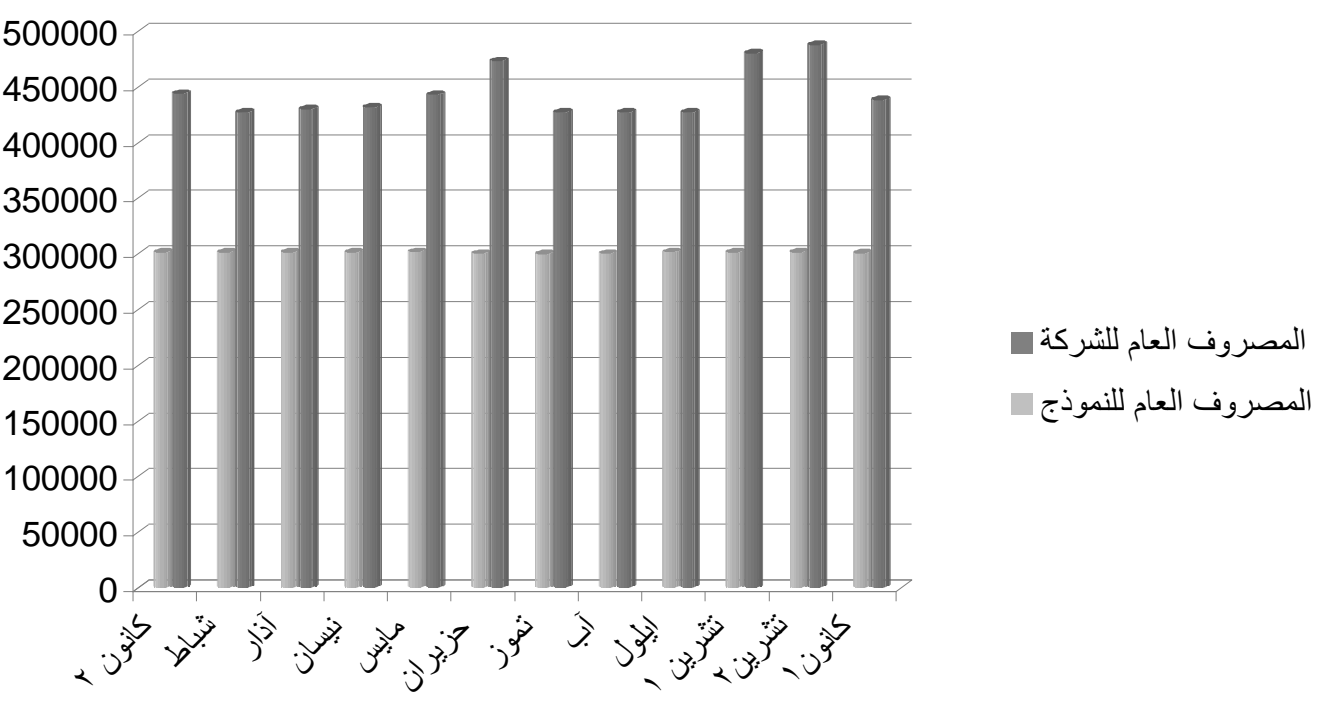

[1] 1 [اثشيوة، حسن عبد الله، "بحوث العمليات"، دار اليازوري العملية للنشر والتوزيع، عمـان-الاردن، الطبعة العربية،

[2]Archana Khurana, S. R. Arora, " The Sum of a linear and a linear fractional transportation problem with restricted and enhanced flow " Journal of Interdisciplinary Mathematics, Vol. 9, No. 2, pp. (373-383),2006 .

[3] E.B.Bajalinov , " Linear Fractional programming : Theory, Methods , Applications and Software" , Kluwer Academic publishers , Boston , 2003.

[4] Frederick S. Hillier and Gerald. J. Liberman, "Introduction to Operation Research", GRAW-Hill , (7thed),( 2001) .

[5] H. A. Taha ,"Operations Research: An Introduction" , Pearson Education ,Inc., Eighth Edition, 2007.

[6] Kavita Gupta , S.R.Arora ," Restricted Flow In A Non Linear Capacitated Transportation Problem With Bounds on Rim Conditions" with bounds on rim conditions " European Journal of Operational Research 178 ,pp(718-737) , 2007.

[7] Kalpana Dahiya, Vanita Verma ," Capacitated Transportation problem with bounds on rim conditions " European Journal of Operational Research 178 ,pp (718-737) , 2007.

[8] Kavita Gupta , Shri Ram Arora," Linear Plus Linear Fractional Capacitated Transportation Problem with Restricted Flow " American Journal of Operations Research, vol 3,pp(581-588), 2013 .

[9] Kavita Gupta , S.R. Arora, " Paradox in a Fractional Capacitated Transportation problem" International Journal of Research in IT, Management and Engineering, Volume2, Issue3.

[10]S. Misra, and C. Das, " Solid Transportation problem with lower and upper bound on the rim condition -a note" NZOR, Vol 9, NO2, 1981.

[11] Vishwas Deep Joshi , Nilama Gupta, "Linear fractional transportation problem with varying demand and supply " le matematiche ,pp(3-12),2011 .

مجلتم العلوم الاقتصاديت والإداريتت


Building a mathematical model of the transportation problem under the dynamics of demand restrictions with practical application Abstractl

In this research we built a mathematical model of the transportation problem for data of General Company for Grain Under the environment of variable demand , and situations of incapableness to determining the supply required quantities as a result of economic and commercial reasons, also restrict flow of grain amounts was specified to a known level by the decision makers to ensure that the stock of reserves for emergency situations that face the company from decrease, or non-arrival of the amount of grain to silos, also it took the capabilities of the tanker into consideration and the grain have been restricted to avoid shortages and lack of processing capability, Function has been adopted in the mathematical model goal is a total of two functions: the first linear to reduce the overall costs of the transportation problem And the second linear fractional represent the proportion of public expenditure for the silos to college profits .a balanced model and equivalent to model the original problem has been formulated. The results proved the efficiency of the model in the distribution of the amount of grain where the total cost was reduced to $(24 \%)$ with ensuring the existence of reserve stocks and meet the demand of mills.where the reserve stocks sufficed nearly to a month and half, the mathematical model was solved by using advanced software(LINGO14.0).

KeywordsıTransportation Problem; Linear Plus Linear Fractional; Restricted Flow ,program(LINGO14.0).

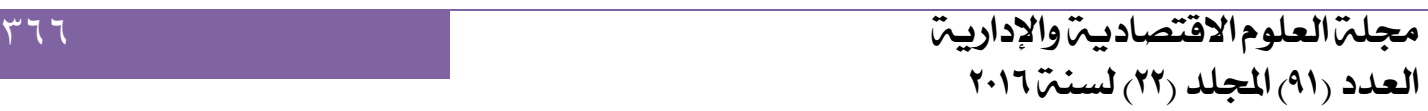

